ARTICLE

Received 13 Oct 2012 | Accepted 16 May 2013 | Published 5 Jul 2013

DOI: $10.1038 /$ ncomms3016

OPEN

\title{
Tetrasaccharide iteration synthesis of a heparin-like dodecasaccharide and radiolabelling for in vivo tissue distribution studies
}

\author{
Steen U. Hansen ${ }^{1, \star}$, Gavin J. Miller ${ }^{1, \star}$, Claire Cole ${ }^{2}$, Graham Rushton ${ }^{2}$, Egle Avizienyte ${ }^{2}$, Gordon C. Jayson ${ }^{2}$ \\ \& John M. Gardiner ${ }^{1}$
}

Heparin-like oligosaccharides mediate numerous important biological interactions, of which many are implicated in various diseases. Synthetic improvements are central to the development of such oligosaccharides as therapeutics and, in addition, there are no methods to elucidate the pharmacokinetics of structurally defined heparin-like oligosaccharides. Here we report an efficient two-cycle $[4+4+4]$ tetrasaccharide-iteration-based approach for rapid chemical synthesis of a structurally defined heparin-related dodecasaccharide, combined with the incorporation of a latent aldehyde tag, unmasked in the final step of chemical synthesis, providing a generic end group for labelling/conjugation. We exploit this latent aldehyde tag for ${ }^{3} \mathrm{H}$ radiolabelling to provide the first example of this kind of agent for monitoring in vivo tissue distribution and in vivo stability of a biologically active, structurally defined heparin related dodecasaccharide. Such studies are critical for the development of related saccharide therapeutics, and the data here establish that a biologically active, synthetic, heparin-like dodecasaccharide provides good organ distribution, and serum lifetimes relevant to developing future oligosaccharide therapeutics.

\footnotetext{
${ }^{1}$ Faculty of EPS, School of Chemistry, Manchester Institute of Biotechnology, The University of Manchester, 131 Princess Street, Manchester M1 7DN, UK. ${ }^{2}$ School of Cancer and Enabling Sciences, The University of Manchester, Wilmslow Road, Manchester M20 4BX, UK. * These authors contributed equally to this work. Correspondence and requests for materials should be addressed to J.M.G. (email: gardiner@manchester.ac.uk).
} 
eparin and heparan sulphate (H/HS) are ubiquitous linear polysulphated oligosaccharides of the glycosaminoglycan (GAG) family, comprising a repeating disaccharide unit. Because of its structural heterogeneity, H/HS is crucially involved in regulating a myriad of cell signalling pathways through modulation of interactions between cytokines and their receptors. This is typified through its involvement in the mediation of fibroblast growth factor (FGF)-regulated cell phenotypes, such as proliferation, adhesion, motility and angiogenesis ${ }^{1-7}$.

Although methods for the isolation of natural $\mathrm{H} / \mathrm{HS}$ samples from biochemical degradation processes are well-established ${ }^{8,9}$, synthetic access to structurally defined H/HS mimetics has also received very significant attention ${ }^{10-36}$. Synthetic access is essential to provide structurally defined $\mathrm{H} / \mathrm{HS}$ oligosaccharide sequences to interrogate the chemical biology of H/HS-mediated processes, a better understanding of which also offers the potential to aid development of new disease treatments ${ }^{37-41}$. The potential development of such oligosaccharides as therapeutics is also dependent on developing tools to determine the pharmacokinetics, distribution and organ availability of these synthetic species. To date, the limitations of synthetic access to suitable tools has precluded such developments for bioactive lead oligosaccharide structures. This presents the need to develop an efficient procedure for the synthesis of longer bioactive heparinlike oligosaccharides, which also provide efficient access to derivatization/conjugation of structurally defined, biologically significant synthetic $\mathrm{H} / \mathrm{HS}$ sequences ${ }^{42-45}$.

Our previous in vitro and in vivo anti-angiogenic assessments of size-fractionated digests ${ }^{46-51}$ and subsequent evaluation of a matrix of structurally defined synthetic oligosaccharides ${ }^{52}$ indicated that longer [GlcNS-IdoA2S]-containing species were more effective inhibitors of FGF2, and identified the methyl glycoside analogue of dodecasaccharide 1 ([GlcNS-IdoA2S $]_{6}$ $\mathrm{OMe}$ ) as the optimum lead FGF2 and vascular endothelial growth factor antagonist ${ }^{52}$ (ex vivo evaluation of the synthetic dodecasaccharide [GlcNS-IdoA2S $]_{6}$-OMe confirmed that at biologically active concentrations inhibiting FGF signalling, there was no statistically significant impact on anticoagulation, an important feature required for potential development of therapeutic synthetic saccharides of this type).

Here we report a powerful addition to the field of synthetic heparanoid chemistry, which demonstrates an efficient chemical synthesis of this structurally defined [GlcNS-IdoA2S ${ }_{6}$ heparinlike lead dodecasaccharide $\mathbf{1}$, bearing a terminal latent aldehyde tag (LAT), in just two iterative cycles and four steps from a precursor tetrasaccharide. Concomitant LAT release in a finalstep modification of the oligosaccharide is applied to ${ }^{3} \mathrm{H}$ radiolabelling of dodecasaccharide $\mathbf{1}$ with minimal structural impact. This demonstrates the viability of the approach for rapid, iterative synthetic access to large oligosaccharides on useful scales, which are suitable for biological conjugations and labelling. The tritium radiolabelled analogue $\mathbf{1}$, which provides a new tool to determine the pharmacokinetics of the synthetic oligosaccharide and establish the organ distribution and in vivo lifetime of the lead dodecasaccharide 1, critical factors for the potential development of HS oligosaccharide therapeutics.

\section{Results}

Strategy and end labelling. The end modification of oligosaccharides (via ring opening of the terminal acetal unit, for example, for attaching fluorophores) is an established method for labelling native heparin and related GAGs to facilitate their separation or analysis ${ }^{53,54}$. A number of examples have also employed amide derivatization of the uronic carboxylates to introduce fluorescent or spin labels, or to attach conjugates ${ }^{55,56}$.
There are also a range of uses of modified $O$-glycosides recently employed for conjugation, surface and nanoparticle/dendrimer attachments ${ }^{42-45}$, including applications of click chemistry, in particular the Huisgen reaction.

However, an alternative approach was needed to ensure compatibility with the deprotection/labelling conditions during synthesis and introducing minimal change to the polarity/ functional groups of the oligosaccharide. Thus, a 1,2-diol moiety at the reducing end was incorporated as an LAT. Having an additional O4-sulphate at the non-reducing end of the deprotected dodecasaccharide would allow complete selectivity in a final-stage periodate-mediated cleavage of the LAT to liberate a reactive aldehyde tag (RAT) directly on the final oligosaccharide, thus allowing facile reductive labelling or facilitating other conjugations. Our approach was to develop this LAT incorporation concurrently with the aforementioned tetrasaccharide iteration strategy (Fig. 1).

Synthesis of tetrasaccharide building blocks. The synthetic strategy envisaged using one precursor disaccharide building block, 2 , to provide a single tetrasaccharide unit, 7 , which would function both as an iterative donor (as its O4-trichloroacetyl derivative 8) and as an immediate precursor to an LAT-bearing tetrasaccharide, serving as the initial acceptor tetrasaccharide.

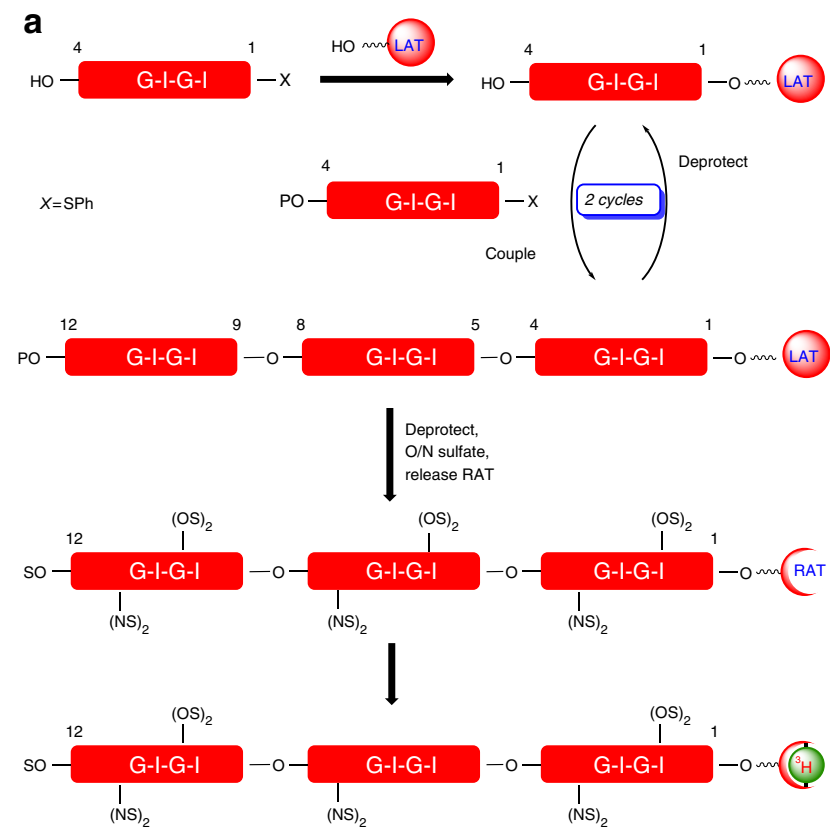

b

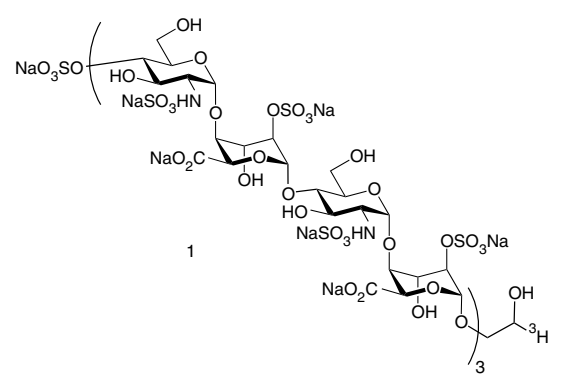

Figure 1 | Strategy for synthesis of end-labelled dodecassacharide.

(a) Iterative $[4+4+4]$ oligosaccharide synthesis strategy with final step RAT release and labelling. G, Glucosamine unit; I, iduronate unit; $P$, trichloroacetyl; $\mathrm{S}, \mathrm{SO}_{3} \mathrm{Na}$; LAT, latent aldehyde tag; RAT, reactive aldehyde tag. (b) Structure of radiolabelled dodecasaccharide. 
Disaccharide 2 was prepared as reported previously, exploiting our scalable iduronate thioglycoside acceptor capabilities for constructing such reagents ${ }^{57,58}$, and is a reverse of the common IdoA-GlcN disaccharide repeat unit seen in several previous heparin-related syntheses ${ }^{10-36}$. Disaccharide 2 was divergently elaborated into trichloroacetimidate donor $\mathbf{4}$ (see Supplementary Figs S5-S12) via free sugar disaccharide 3 (see Supplementary Figs S1-S4) and acceptor 5, with these two building blocks then efficiently coupled to afford tetrasaccharide 6 (Fig. 2; see Supplementary Figs S13-S17). Deprotection at the nonreducing end terminus of 6 then provided the required tetrasaccharide 7 (see Supplementary Figs S18-S22), which was also protected as its O4-TCA derivative $\mathbf{8}$ (see Supplementary Figs S23-S31), thereby providing two potential tetrasaccharide donor modules (6 and 8 ), differing only in their non-reducing terminal O4-protecting group.

Synthesis of tetrasaccharide 6 was similarly efficient whether thioglycoside acceptor $\alpha-5$ or $\beta-5$ was employed, providing access to either tetrasaccharide $\alpha-7$ or $\beta-7$, respectively, both of which can function in the subsequent iterative homologations to effect the same $\alpha$-selective glycosylations of the desired oligosaccharide acceptor. These tetrasaccharides can readily be accessed on hundreds of milligram to multigram scale.

Notably, and further enhancing the overall synthetic efficiency, although 7 has both acceptor (4-OH) and donor (1-SPh) functionality, this material could be directly glycosylated at the reducing terminus without the need for protection at $\mathrm{O} 4$. The installation of the required LAT was thus effected using a dibenzylated glycerol unit, designed for its ultimate deprotection to the required diol concomitant with the penultimate debenzylation of the protected heparin oligosaccharide. Hence, 7 was glycosylated with (S)-2,3-dibenzyloxy propanol affording the reducing end-modified tetrasaccharide acceptor 9 (see Supplementary Figs S32-S36) directly, with the non-reducing terminus already in place as an acceptor for the first tetrasaccharide homologation (Fig. 3).

Coupling of acceptor 9 and tetrasaccharide donors $\mathbf{6}$ or $\mathbf{8}$, hence, generated the octasaccharides 10 (see Supplementary Figs S37-S39) and 11 (see Supplementary Figs S40-S44), respectively, with complete $\alpha$-anomeric selectivity. This now further establishes that the iduronate donor-terminated tetrasaccharides can function as efficient oligosaccharide homologation building blocks using longer acceptors (a previous GlcN-GlcA-GlcN-IdoA tetrasaccharide had been shown to be effective as a donor for monosaccharide acceptors $)^{24}$ and compliments such a capability exploited using GlcN donor systems ${ }^{24,44}$. This also thereby underpins a capability to now access other long $[\mathrm{GlcN}-\mathrm{IdoA}]_{\mathrm{n}^{-}}$based sequences using such an accelerated iterative strategy.

Synthesis of oligosaccharide via $[4+4+4]$ two-cycle iteration. During the deprotection of $\mathrm{O} 4$ of octasaccharide 10, it was found that the ceric ammonium nitrate mediated p-methoxybenzyl removal gave a mixture of products, although the TCA group of analogue $\mathbf{1 1}$ could be removed in excellent yield using novel mild conditions. Combined with the higher glycosylation yields obtained, this led to selection of the O4-TCA tetrasaccharide $\mathbf{8}$ for further iterations. Deprotection of octasaccharide 11 provided
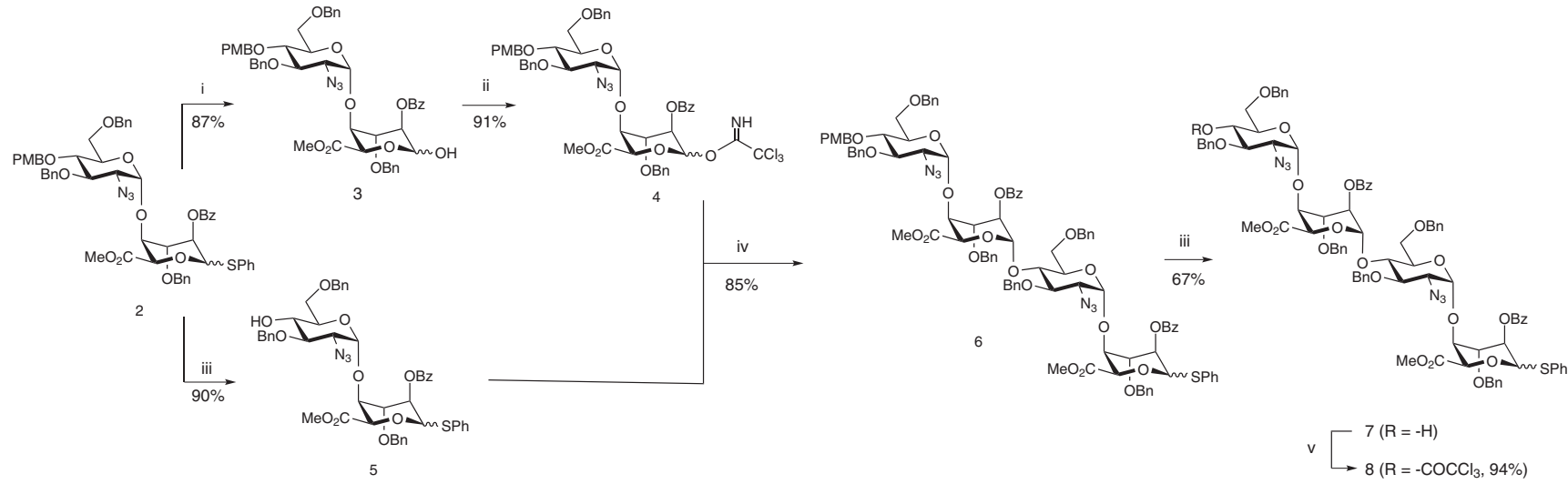

Figure 2 | Synthesis of core tetrasaccharide donor/acceptor modules. (i) NBS, acetone. (ii) $\mathrm{CCl}_{3} \mathrm{CN}, \mathrm{DBU}, \mathrm{DCM}$. (iii) $\mathrm{CAN}, \mathrm{CH}_{3} \mathrm{CN} / \mathrm{H}_{2} \mathrm{O}$. (iv) $\mathrm{TMSOTf}$ DCM. (v) $\mathrm{CCl}_{3} \mathrm{COCl}$, pyridine, DCM.

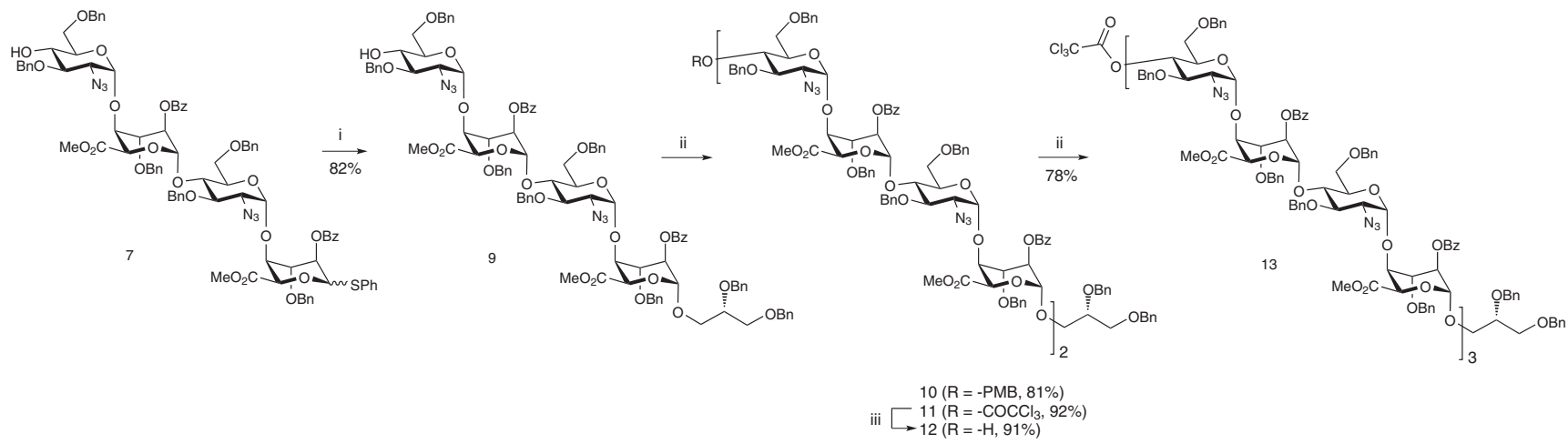

Figure 3 | Iterative [4+4+4] dodecasaccharide synthesis. (i) (S)-2,3-bis(benzyloxy)propanol, NIS, AgOTf (cat.), DCM. (ii) 6 or 8, NIS, AgOTf (cat.), DCM. (iii) $\mathrm{MeOH}$ /pyridine (5:2). 
acceptor octasaccharide 12 (see Supplementary Figs S45-S49) as a substrate, enabling a second cycle of iterative coupling with donor module 8, providing thereby protected dodecasaccharide 13 (see Supplementary Figs S50-S54) and completing the efficient and rapid two-cycle iteration. The overall four-step yield from tetrasaccharide 7 to protected dodecasaccharide 13 was 54\%, yielding around $300 \mathrm{mg}$ of this oligosaccharide, a significant scale for such rapid dodecasaccharide assembly.

From protected dodecasaccharide 13, concurrent saponification, $O$-sulphation, debenzylation/azide reduction and finally $\mathrm{N}$-sulphation provided the fully deprotected and regiospecifically sulphated dodecasaccharide 14 (see Supplementary Figs S59-S64) bearing the free 1,2-diol LAT unit at the reducing terminus (Fig. 4).

Nuclear magnetic resonance provides unambiguous definition of the complete $N$-sulphation, evidenced by the clear difference in shift of the $\mathrm{H}-2$ protons on converting the 2-amino to 2-NS functionality (Fig. 5). Differentiation of the NS of the non-reducing terminal glucosamine 2-NS is evident (the only ring with O4-S) and confirmed by clear correlation spectroscopy correlations (see Supplementary Fig. S60). The clear resolution of signals for the reducing terminal iduronate is clear, and on oxidative cleavage the spectrum for the RAT-terminated dodecasaccharide shows a clear set of two doublets $(1.3: 1)$ for the RAT methylene. These are not mutually coupled and the nonequivalent integration would also be consistent with these arising from acetal formation, transiently retaining the LAT aldehyde in a seven-membered ring hemiacetal. This is also consistent with changes in the shifts of $\mathrm{H} 5$ and $\mathrm{H} 2$ of the reducing terminal iduronate. In addition, the $\mathrm{H}-5$ of ring $\mathrm{A}$ is well separated and the small coupling constant for those protons, also evident for the other overlapping $\mathrm{H} 5$ protons, shows that these long sulphated oligosaccharides do sit largely in the ido ${ }^{1} \mathrm{C}_{4}$ conformation.

Oxidative cleavage was effected in near-quantitative yield with sodium periodate, unveiling the target-reducing end aldehyde in the form of reactive conjugate, 15 (see Supplementary Figs S65-S67).

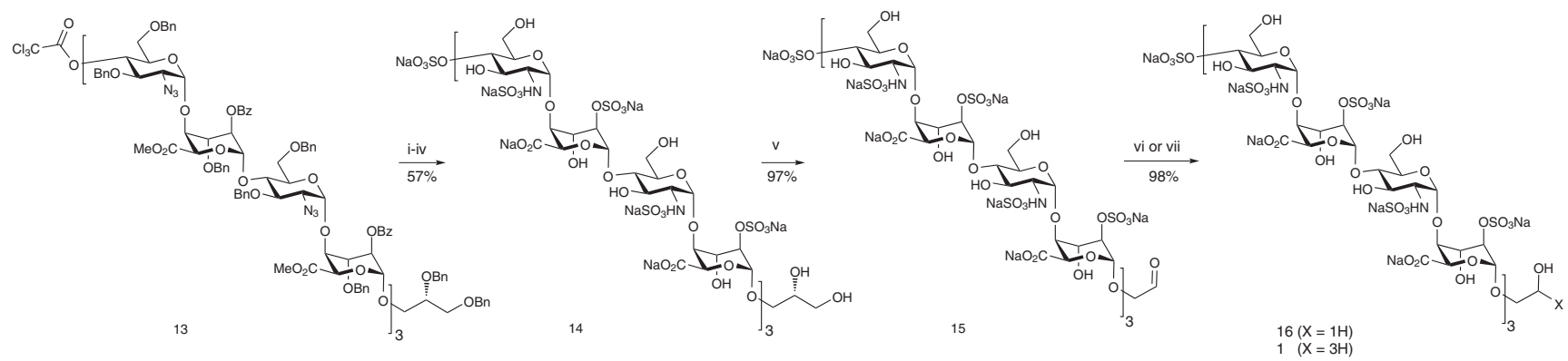

Figure 4 | Dodecasaccharide deprotections and end labelling. (i) $\mathrm{LiOH}$, tetrahydrofuran (THF)/ $\mathrm{MeOH} / \mathrm{H}_{2} \mathrm{O}, 74 \%$. (ii) $\mathrm{Py} . \mathrm{SO}_{3}$ complex, pyridine, 80\%. (iii) $\mathrm{H}_{2}, \mathrm{Pd}(\mathrm{OH})_{2} / \mathrm{C}, \mathrm{MeOH} / \mathrm{THF} / \mathrm{H}_{2} \mathrm{O}$ 2:1:1, 96\%. (iv) $\mathrm{Py}_{5} \mathrm{SO}_{3}$ complex, $\mathrm{NaHCO}_{3}, \mathrm{H}_{2} \mathrm{O}, 100 \%$. (v) $\mathrm{NalO}_{4}, \mathrm{H}_{2} \mathrm{O}$. (vi) $\mathrm{NaBH}_{4}, \mathrm{H}_{2} \mathrm{O}$. (vii) $\mathrm{NaB}^{3} \mathrm{H}_{4}, \mathrm{H}_{2} \mathrm{O}$.

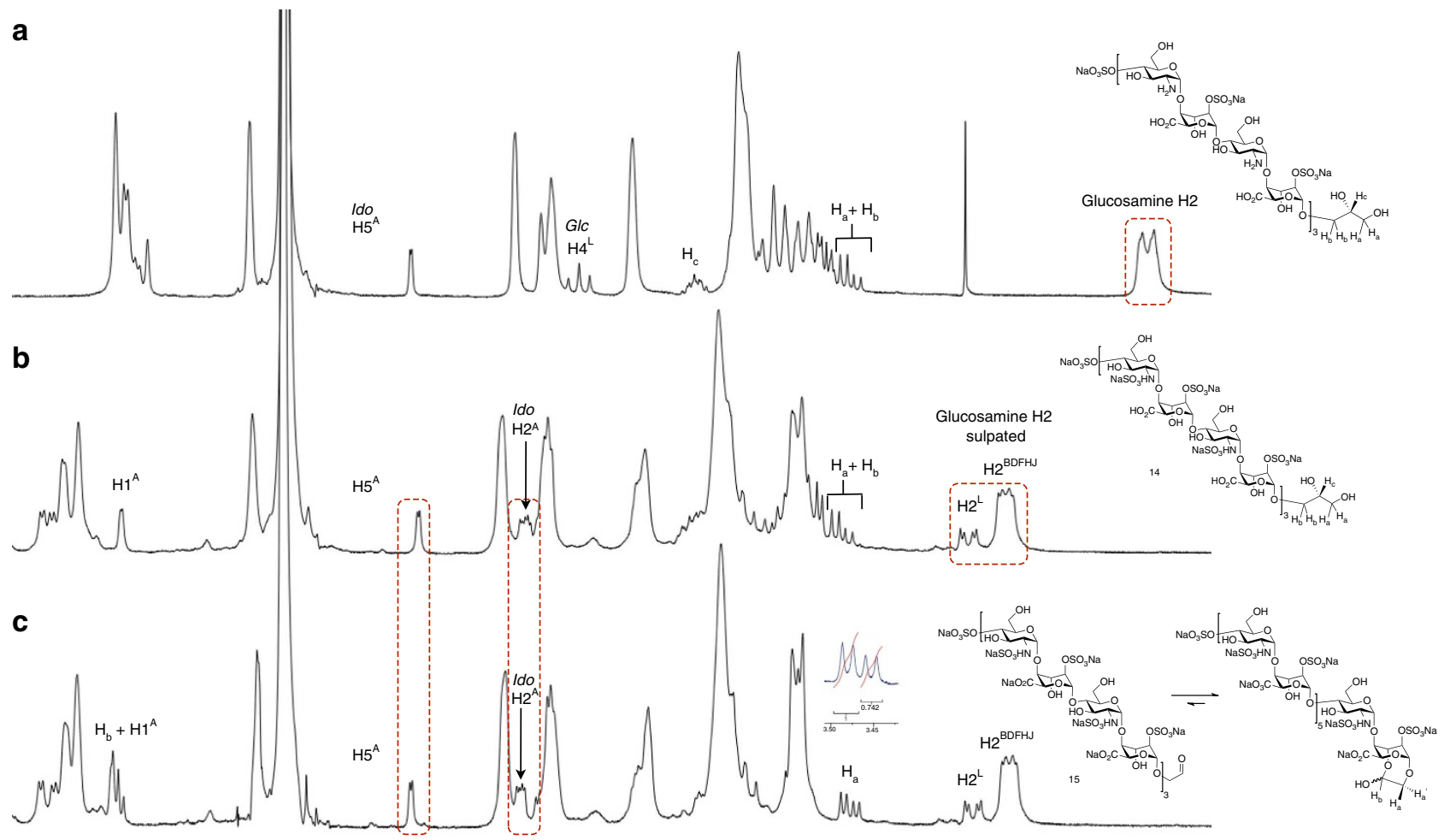

Figure 5 | Nuclear magnetic resonance confirmation of dodecasaccharide $\mathbf{N}$-sulphation and comparisons of diol LAT and oxidatively cleave RAT. (a) Intermediate amino containing dodecasaccharide. (b) $\mathrm{N}$-sulphated dodecasaccharide. (c) Oxidatively cleaved RAT-terminated oligosaccharide. 
To introduce the tritium label, 15 was then treated with $\mathrm{NaB}^{3} \mathrm{H}_{4}$ under basic conditions at $45^{\circ} \mathrm{C}$ (following cold-label method evaluations on a disaccharide model and the unlabelled reduction of 15 to 16 (see Supplementary Figs S68-S70)).
After ensuring the reaction was complete by addition of excess $\mathrm{NaBH}_{4}$ and quenching, the sample was desalted on Sephadex G-25 to remove excess reducing agent. Radiolabelled 1 was then further purified by size-exclusion chromatography (Fig. 6) and

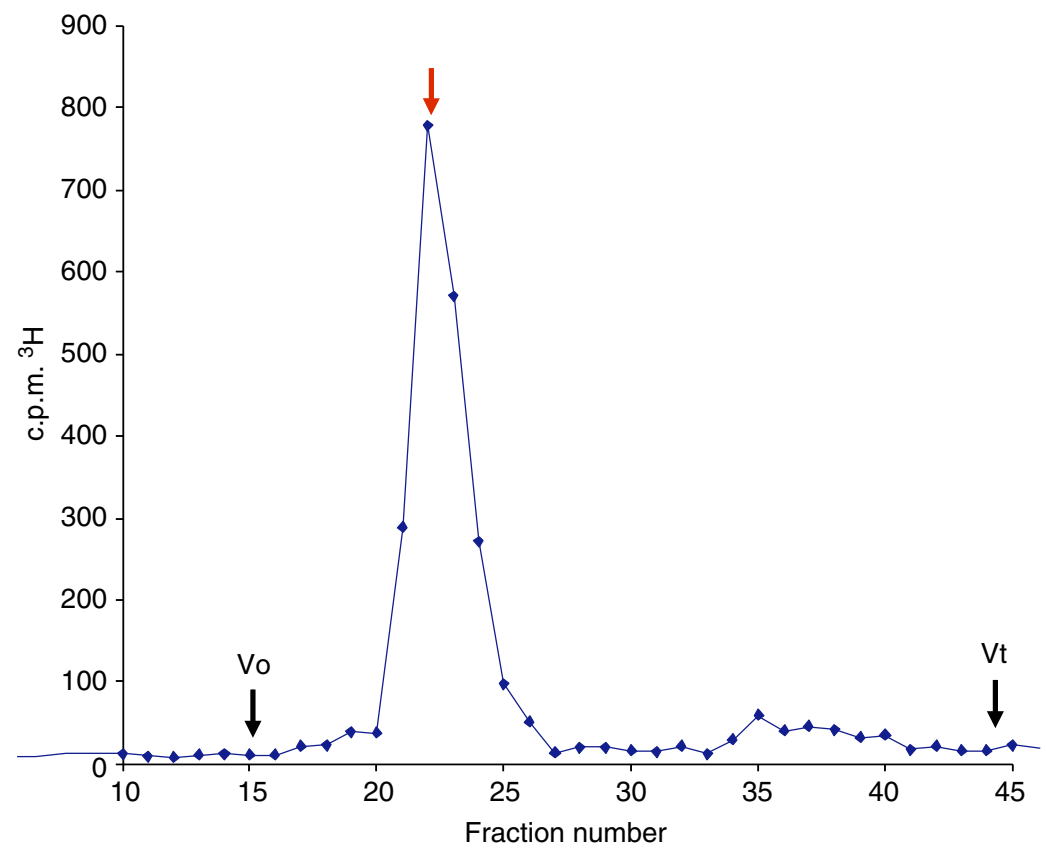

Figure 6 | HPLC size-exclusion chromatogram of 1 on Superdex. To confirm the oligomer size of ${ }^{3} \mathrm{H}-1$ HPLC size-exclusion chromatography on Superdex 75 indicated the ${ }^{3} \mathrm{H}-\mathbf{1}$ elutes (red arrow) at position identical to de-6-O-sulphated dodecasaccharide heparin standard. Vo, excluded volume; Vt, total column volume.
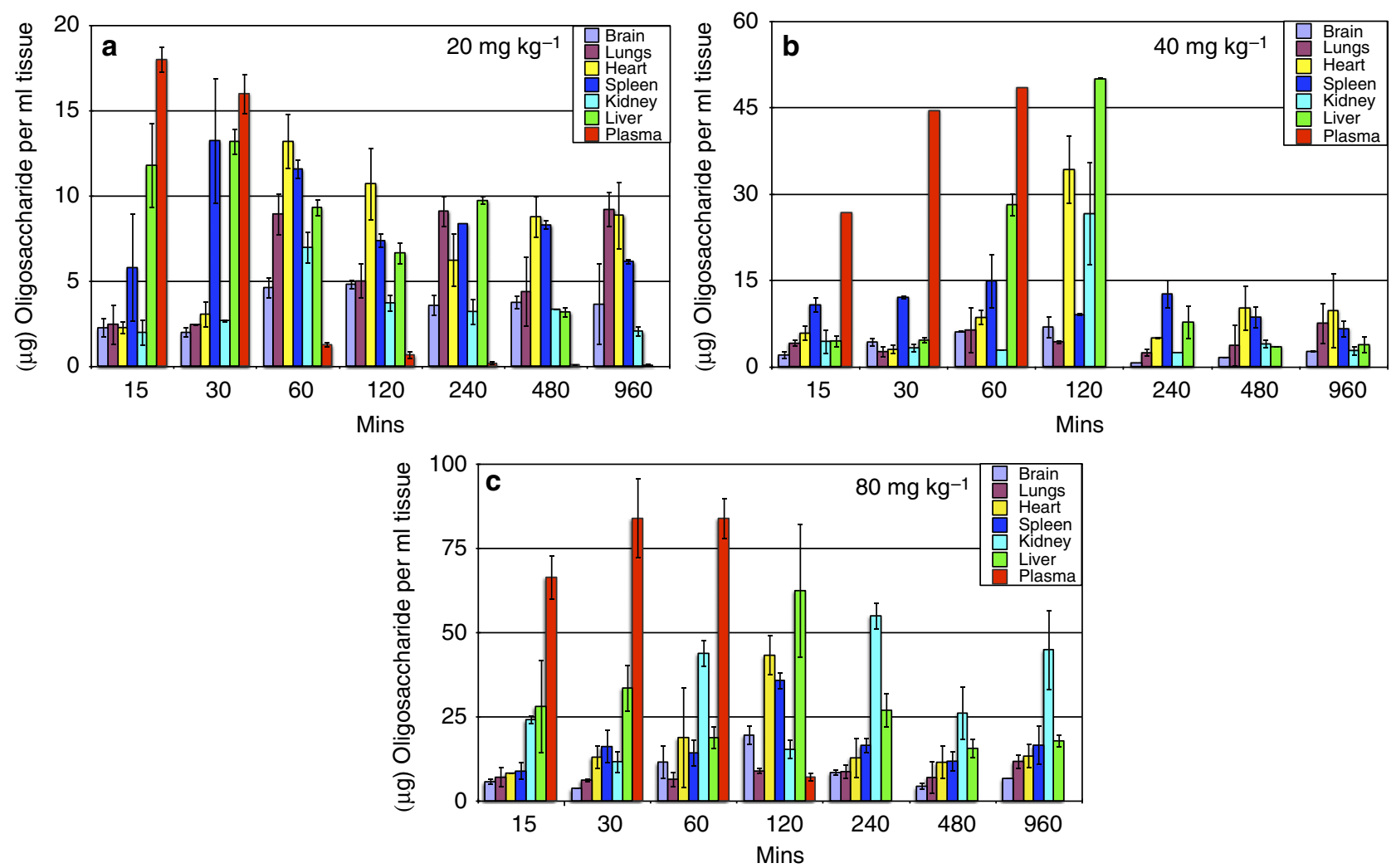

Figure 7 | Tissue localisation of 1. Mice (two) were injected with 20 (a), 40 (b) or $80 \mathrm{mg} \mathrm{kg}^{-1}$ (c) of 1. Tissue quantities are presolublization. Error bars represent the s.e.m. of c.p.m. converted to oligo weight using specific activity. 


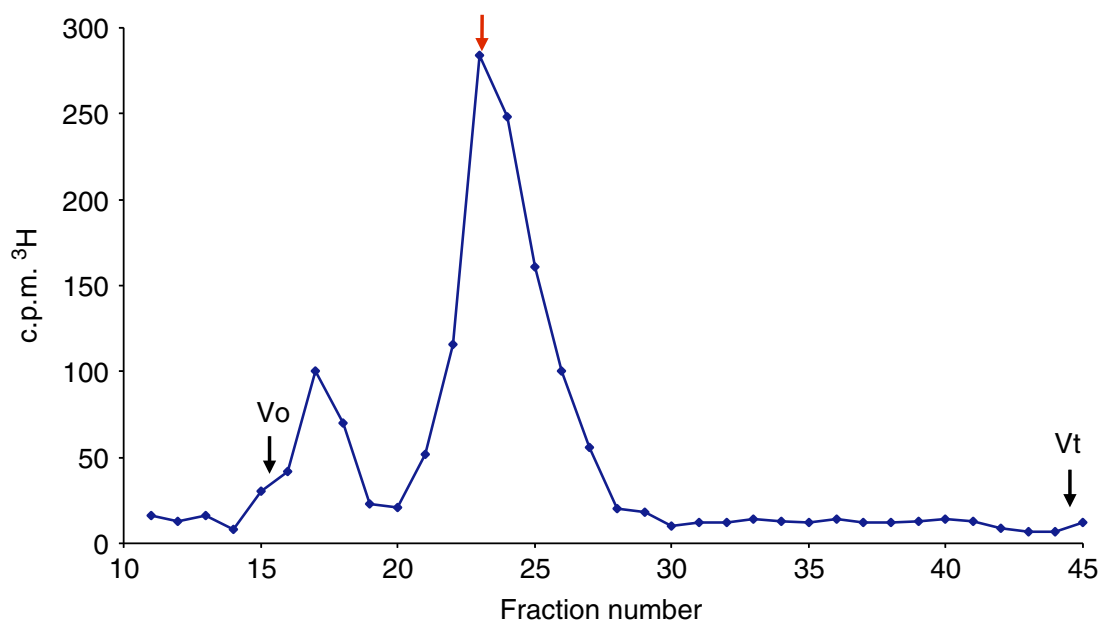

Figure 8 | HPLC SEC of 1 injected s.c. into mice and then extracted and purified from kidneys $\mathbf{4 h}$ after injection. Radiolabelled oligosaccharide 1 was injected s.c. into mice and then extracted and purified from kidneys $4 \mathrm{~h}$ after injection (see Methods). Radiolabelled oligosaccharide $\mathbf{1}$ was subjected to HPLC chromatography on a Superdex 75 size-exclusion column. Red arrow shows elution of ${ }^{3} \mathrm{H}-\mathbf{1}$ (see Fig. 5). Vo, excluded volume; Vt, total column volume.

was eluted from the column in good accordance with an established de-6-O-sulphated dodecasaccharide heparin standard. The specific activity of 1 was determined to be $5.5 \times$ $10^{6}$ c.p.m. $\mathrm{mg}^{-1}$ of oligosaccharide, suitable for the required in vivo evaluations.

Applications of radiolabelled heparin dodecasaccharide 1 . Radiolabelled heparin-mimetic 1 was thus employed to determine its in vivo clearance and tissue distribution in mice (the biological efficacy of the OMe analogue of which we had previously established in vitro $)^{52}$.

The mice were dosed subcutaneously (s.c.) with 20, 40 and $80 \mathrm{mg} \mathrm{kg}^{-1}$ of oligosaccharide spiked with 140,000 c.p.m. of ${ }^{3} \mathrm{H}$ 12 -mer 1 as a radiotracer. Tissue concentrations were determined from the level of radiolabelled oligosaccharide in tissue samples of known mass during a 16 -h period (Fig. 7). A maximum plasma concentration of $18 \mu \mathrm{g} \mathrm{ml}^{-1}$ was observed $15 \mathrm{~min}$ after dosing mice with $20 \mathrm{mg} \mathrm{kg}^{-1}$ of oligosaccharide (Fig. 6a). When dosed with 40 or $80 \mathrm{mg} \mathrm{kg}^{-1}$, maximum plasma concentrations of 44.8 and $84.0 \mu \mathrm{g} \mathrm{ml}^{-1}$, respectively, were observed after $60 \mathrm{~min}$ (Fig. 6b,c). Critically, these data demonstrate that the plasma concentration of oligosaccharide in vivo was sufficient to inhibit the biological activity of FGF2 based on in vitro data ${ }^{52}$.

All tissues, except lungs, showed a time-dependent accumulation of 1 at all doses, and the maximum concentrations increased with a higher initial dose (Fig. 6). The highest concentration of $\mathbf{1}$ was detected in tissues when mice were treated with $80 \mathrm{mg} \mathrm{kg}^{-1}$. In addition, all tissues, except the liver, attained maximal levels of 1 by $120 \mathrm{~min}$. The tissue distribution data described here show that at 40 and $80 \mathrm{mg} \mathrm{kg}^{-1}$, biologically active concentrations 52 were achieved in the liver, lungs and spleen within a 2-h period. The half-life of oligosaccharides in mice was estimated to be $\sim 2 \mathrm{~h}$. As murine clearance is so rapid, this result is particularly encouraging for the development of oligosaccharide therapeutics.

From the results shown in Fig. 6, there is good evidence for sustained plasma concentrations of 1 up to around $1 \mathrm{~h}$ at the two higher dose levels and that the oligosaccharide is well retained in the plasma at these concentrations. At lower doses, there is a more even distribution among the examined tissues, suggesting that higher doses would be needed to sustain sufficient oligosaccharide concentration in plasma.
To assess the metabolic stability of $\mathbf{1}$ in vivo, we extracted and purified ${ }^{3} \mathrm{H}$-12-mer 1 from mouse kidney after a 4-h treatment, to determine the extent of any degradation or metabolism. The majority of the material eluted in a single peak of 3,500 Da, which corresponds to a mass of dodecasaccharide 1 (Fig. 8).

\section{Discussion}

This $[4+4+4]$ iterative oligosaccharide approach thus provides an efficient two-cycle synthesis of a structurally defined HS dodecasaccharide, illustrating that iduronate donor tetrasaccharides function as effective and selective glycosyl donors with extended saccharide acceptors. The reduction here in the number of synthetic steps taken to assemble these longer heparanoids significantly enhances their accessibility, and the inclusion of the end label via glycosylation (avoiding $\mathrm{O} 4$ protection) to directly afford an endtagged tetrasaccharide acceptor also adds to the abbreviation of the synthetic route. Notably, homologation here using 4-mer and 8mer acceptors with this longer donor is shown to perform with an efficiency that remains high, even for a $[4+8]$ coupling. The efficiency of this tetrasaccharide-iteration-based synthetic route also facilities the viability of new opportunities for sequence versatility and applications to other diverse conjugation targets.

The synthesis and inclusion of the LAT described here offers a unique strategy for discrete end labelling of this heparin-like structure, such that the label will not interfere with the ligandbinding potential of the molecule, and the small structural change would be anticipated to minimize effects on pharmacokinetics. The end-terminal latent tag offers generality for incorporation into other heparanoids.

Utility of this end group for radiolabelling provides the first example of using a structurally defined heparin-like dodecasaccharide to quantify in vivo tissue distribution and metabolic stability. Conventional pharmacological development of heparin has relied on its anticoagulant properties that can be measured in patients using universally available tests of the clotting cascade. However, the lack of anticoagulant activity of structurally defined synthetic HS oligosaccharides, although important for nonanticoagulant drugs, also presents the problem of how to measure the pharmacokinetics and metabolism of such novel synthetic heparin-like oligosaccharides in vivo. Here we report for the first time a novel solution to this problem that should greatly assist the 
preclinical and clinical development of potential oligosaccharide therapeutics. In this dodecasaccharide case, this study has shown that the dodecasaccharide has good in vivo stability, and strongly indicates that oligosaccharide drugs of this type have a high prospect of effective dose distribution and stability on therapeutically valid timescales.

\section{Methods}

Synthesis of dodecasaccharide 12. Octasaccharide $11(346 \mathrm{mg}, 0.10 \mathrm{mmol})$ was dissolved in a mixture of $\mathrm{MeOH} /$ pyridine $(5 \mathrm{ml}$ per $2 \mathrm{ml})$ and heated to $50^{\circ} \mathrm{C}$ for $4 \mathrm{~h}$. The solvents were evaporated and coevaporated with toluene $(2 \times 20 \mathrm{ml})$. The crude product was purified using flash column chromatography (EtOAc/hexane 1:2 and 3:5). This yielded $12(300 \mathrm{mg}, 91 \%)$ as a white foam, along with recovered starting material $(20 \mathrm{mg}, 5 \%) . R_{\mathrm{f}} 0.10(\mathrm{EtOAc} /$ hexane $1: 2) .[\alpha]_{\mathrm{D}}^{20}=+9.8\left(c=0.32, \mathrm{CH}_{2} \mathrm{Cl}_{2}\right)$. Mass spectrometry (MS) matrix-assisted laser desorption/ionization-time of flight: $m / z$ : calcd for $\mathrm{C}_{181} \mathrm{H}_{184} \mathrm{~N}_{12} \mathrm{NaO}_{47}[M+\mathrm{Na}]^{+}:$3300.2; found: 3300.2. Elemental analysis calcd (\%) for $\mathrm{C}_{181} \mathrm{H}_{184} \mathrm{~N}_{12} \mathrm{O}_{47}$ : C 66.29, $\mathrm{H} \mathrm{5.66,} \mathrm{N} \mathrm{5.13;} \mathrm{found} \mathrm{C} 66.57$, H 5.98, N 4.96 (see Supplementary Methods for further characterization data).

Synthesis of dodecasaccharide 13. Acceptor $12(252 \mathrm{mg}, 0.077 \mathrm{mmol})$ and donor $8(175 \mathrm{mg}, 0.100 \mathrm{mmol})$ were dissolved in dry dichloromethane (DCM) $(4 \mathrm{ml})$ under $\mathrm{N}_{2}$. Freshly activated $4 \AA$ powdered molecular sieves $(222 \mathrm{mg})$ were added and the solution cooled to $0^{\circ} \mathrm{C}$ in an ice bath. After $10 \mathrm{~min}$ NIS $(47 \mathrm{mg}, 0.21 \mathrm{mmol})$ was added, and after another $10 \mathrm{~min}$ AgOTf (catalytic amount) was added. The suspension changed colour from pale yellow to deep red and was stirred for a further $35 \mathrm{~min}$. The reaction was quenched into a separating funnel containing a mixture of DCM $(50 \mathrm{ml})$, saturated aqueous $\mathrm{NaHCO}_{3}(50 \mathrm{ml})$ and $\mathrm{Na}_{2} \mathrm{~S}_{2} \mathrm{O}_{3}(5 \mathrm{ml}$, $10 \%$ aqueous). After shaking until the iodine colour was removed, the suspension was filtered through a short pad of Celite washing with water and DCM. The layers were separated and the aqueous layer extracted with DCM $(10 \mathrm{ml})$. The organic layers were combined, dried $\left(\mathrm{MgSO}_{4}\right)$ and the solvent removed in vacuo. The crude product was purified by silica gel flash column chromatography (EtOAc/hexane 7:13) to yield 13 (295 $\mathrm{mg}, 78 \%$ ) as a white foam (recovered acceptor (37 mg, 15\%)). $[\alpha]_{\mathrm{D}}^{20}=+18.1\left(c=0.68, \mathrm{CH}_{2} \mathrm{Cl}_{2}\right)$. MS matrix-assisted laser desorption/ionizationtime of flight: $m / z$ : calcd for $\mathrm{C}_{265} \mathrm{H}_{265} \mathrm{Cl}_{3} \mathrm{~N}_{18} \mathrm{NaO}_{70}[M+\mathrm{Na}]^{+}: 4946.7$; found: 4946.6. Elemental analysis calcd (\%) for $\mathrm{C}_{265} \mathrm{H}_{265} \mathrm{Cl}_{3} \mathrm{~N}_{18} \mathrm{O}_{70}$ : C 64.58, H 5.42, N 5.12; found C 63.91, H 5.41, N 5.06 (see Supplementary Methods for further characterization data).

Synthesis of dodecasaccharide sodium salt 14. Saponifications. Dodecasaccharide $13(257 \mathrm{mg}, 0.052 \mathrm{mmol})$ was dissolved in tetrahydrofuran $(5 \mathrm{ml})$ and $\mathrm{MeOH}(1.5 \mathrm{ml})$, and then cooled to $0{ }^{\circ} \mathrm{C}$ in an ice bath. Then, $\mathrm{LiOH} . \mathrm{H}_{2} \mathrm{O}(55 \mathrm{mg}$, $1.30 \mathrm{mmol}$ ) dissolved in $1 \mathrm{ml}$ water was added dropwise over $10 \mathrm{~min}$. The solution was stirred for $5 \mathrm{~h}$ at $0{ }^{\circ} \mathrm{C}$, and then at room temperature for another $19 \mathrm{~h}$. The solution was then extracted with EtOAc $(2 \times 50 \mathrm{ml})$ and $\mathrm{HCl}(0.2 \mathrm{M}, 40 \mathrm{ml})$, dried $\left(\mathrm{MgSO}_{4}\right)$, filtered and evaporated. The crude product was purified using flash column chromatography (DCM/MeOH 30:1). This yielded the carboxylic acid dodecasaccharide intermediate product $\mathbf{A}(174 \mathrm{mg}, 74 \%)$ as a white solid. $R_{\mathrm{f}} 0.18$ (DCM/MeOH 20:1), then used directly in the next step.

Sulphation of hydroxyls. The dodecasaccharide intermediate A (170 mg, $0.042 \mathrm{mmol}$ ) was dissolved in dry pyridine $(5 \mathrm{ml})$, pyridine sulphur trioxide complex $(140 \mathrm{mg}, 0.88 \mathrm{mmol})$ added and then heated to $50{ }^{\circ} \mathrm{C}$ in an oil bath for $8 \mathrm{~h}$. The solution was stirred at room temperature for another $12 \mathrm{~h}$. The reaction was quenched with $\mathrm{MeOH}$ and then evaporated. The crude product was redissolved in $\mathrm{MeOH} / \mathrm{DCM}(10 \mathrm{ml} / 5 \mathrm{ml})$, stirred with Amberlite IR-120 Na resin $(1.3 \mathrm{~g})$ for $8 \mathrm{~h}$, filtered, resin washed with $\mathrm{MeOH}(2 \times 5 \mathrm{ml})$ and the filtrate evaporated. This residue was then purified using flash column chromatography (DCM/MeOH 20:1). This yielded 2-O-sulphated dodecasaccharide intermediate B $(160 \mathrm{mg}, 80 \%)$ as a white solid.

Hydrogenolysis of benzyls and azides. The IdoA2S benzylated 2-azido-containing dodecasaccharide intermediate $\mathbf{B}(132 \mathrm{mg}, 0.027 \mathrm{mmol})$ was dissolved in a mixture of $\mathrm{MeOH} /$ tetrahydrofuran $(4 \mathrm{ml} / 2 \mathrm{ml})$, and $\mathrm{NaHCO}_{3}(14 \mathrm{mg}, 0.165 \mathrm{mmol})$ dissolved in $2 \mathrm{ml}$ of water was added, atmosphere exchanged for nitrogen and $\mathrm{Pd}(\mathrm{OH})_{2} / \mathrm{C}(120 \mathrm{mg}, 10-20 \%)$ added, and again flushed with nitrogen. The nitrogen balloon was replaced with a hydrogen balloon and atmosphere replaced with hydrogen. The reaction was heated to $40^{\circ} \mathrm{C}$ in an oil bath for $48 \mathrm{~h}$ with vigorous stirring. The product mixture was filtered through Celite, washed with $\mathrm{MeOH} /$ water $(3 \times 3 \mathrm{ml})$ and water $(3 \times 3 \mathrm{ml})$. The combined filtrate was then evaporated to give dodecasaccharide amine intermediate $\mathbf{C}(78 \mathrm{mg}, 96 \%)$ as a glassy solid (see Supplementary Methods).

Sulphation of amines. The dodecasaccharide amine $(65 \mathrm{mg}, 0.022 \mathrm{mmol})$ was dissolved in water $(4 \mathrm{ml}), \mathrm{NaHCO}_{3}(108 \mathrm{mg}, 1.29 \mathrm{mmol})$ and pyridine sulphur trioxide complex $(97 \mathrm{mg}, 0.61 \mathrm{mmol}$ ) was added with vigorous stirring.
This procedure was repeated after $1.30,3.30,5.30,17.30$ and $19.30 \mathrm{~h}\left(\mathrm{NaHCO}_{3}\right.$ : $109,121,113,110$ and $110 \mathrm{mg} ; \mathrm{Py}_{\mathrm{SO}}$ : 92, 88, 111, 100 and $70 \mathrm{mg}$ ). After $24 \mathrm{~h}$, the mixture was evaporated. The crude containing $\mathrm{Na}_{2} \mathrm{SO}_{4}$ salts was redissolved in minimum amount of water and purified by passage through a Sephadex G-25 column $(40 \mathrm{ml})$ by eluting with water. The fractions containing oligosaccharide were pooled and evaporated to yield $14(78 \mathrm{mg}, 100 \%)$ of as a glassy solid. High-resolution MS (Fourier transform MS): $m / z$ : calcd for $\mathrm{C}_{75} \mathrm{H}_{111} \mathrm{~N}_{6} \mathrm{Na}_{4} \mathrm{O}_{102} \mathrm{~S}_{13}$ $[M-15 \mathrm{Na}+8 \mathrm{H}]^{-7}: 462.4234$; found: 462.4244 (see Supplementary Methods for structures of intermediates A, B and C, and further characterization data for $\mathbf{B}$ C and 14, and Supplementary Figs 56-59 for spectra of A-C).

Synthesis of dodecasaccharide aldehyde 15. The dodecasaccharide $14(61 \mathrm{mg}$, $0.017 \mathrm{mmol})$ was dissolved in water $(1 \mathrm{ml})$ and sodium periodate $(3.9 \mathrm{mg}$, $0.018 \mathrm{mmol}$ ) was added and stirred for $6 \mathrm{~h}$. The crude was purified by passage through a Sephadex G-25 column by eluting with water. The fractions containing oligosaccharide were pooled and evaporated to yield $58 \mathrm{mg}(97 \%)$ of 15 as a glassy solid (see Supplementary Methods for characterization data).

Synthesis of ${ }^{3} \mathbf{H}$-labelled dodecasaccharide 1. Three micrograms of ${ }^{3} \mathrm{H}$-labelled sodium borohydride $(1 \mathrm{mCi})$ was reacted with $1.2 \mathrm{mg}$ of aldehyde-bearing dodecasaccharide 15 in $20 \mu \mathrm{l}$ of $50 \mathrm{mM} \mathrm{NaOH}$ in a sealed reinforced glass Reacti-Vial at $45^{\circ} \mathrm{C}$ for $2 \mathrm{~h}$. To ensure that all aldehyde was reduced, an excess of unlabelled $1 \mathrm{M}$ sodium borohydride was then added and sample incubated for a further $2 \mathrm{~h}$ at $45^{\circ} \mathrm{C}$. Reaction was halted by the addition of $5 \mu \mathrm{l}$ of $1 \mathrm{M}$ sulphuric acid. Tritium labelled oligosaccharide was then desalted on PD-10 (G-25) column that was preequilibrated with water and $0.5 \mathrm{ml}$ fractions were collected. Labelled oligosaccharide 1, which eluted in fractions 10-14, was collected and freeze-dried. To confirm the size of radiolabelled material, the ${ }^{3} \mathrm{H}$-dodecasaccharide $\mathbf{1}$ was subjected to HPLC size-exclusion chromatography on an Agilent 1200 HPLC system. The sample was run on a Superdex 75 column $(10 \mathrm{~mm} \times 300 \mathrm{~mm}$; GE Healthcare $)$ in PBS at $0.5 \mathrm{ml} \mathrm{min}^{-1}$. Aliquots from $0.5 \mathrm{ml}$ fractions were taken, mixed with $2 \mathrm{ml}$ of Hisafe scintillation fluid (Perkin-Elmer) and ${ }^{3} \mathrm{H}$ level was counted on a Wallac 1400 scintillation counter. An unlabelled de-6-O-sulphated heparin dodecasaccharide (Iduron), which is approximately the same size as synthetic dodecasaccharide 1, was used to calibrate the column and was monitored at $232 \mathrm{~nm}$ by an in-line ultraviolet detector. Fractions containing ${ }^{3} \mathrm{H}$-dodecasaccharide 1 were collected, desalted, freeze-dried and weighed. Specific activity was determined as $5.5 \times 10^{6}$ c.p.m. $\mathrm{mg}^{-1}$ of oligosaccharide.

Pharmacokinetic study of ${ }^{3} \mathbf{H}$-labelled dodecasaccharide $\mathbf{1}$ in mice. ${ }^{3} \mathrm{H}$-Labelled dodecasaccharide 1 was administered to SCID- $b g$ female mice s.c. as a single dose at 20,40 and $80 \mathrm{mg} \mathrm{kg}^{-1}$ and animals were culled at $0.25,0.5,1,2,4,8$ and $16 \mathrm{~h}$ after dosing. Two animals per each treatment group were used. At the time of culling, blood was collected by cardiac puncture. The brain, kidney, liver, spleen, heart and lungs were removed and their weight was measured. Samples were incubated overnight at $60^{\circ} \mathrm{C}$ in $4 \mathrm{ml}$ of Soluene 350 (Perkin-Elmer). Aliquots of $500 \mu \mathrm{l}$ of the resultant tissue solution were taken for scintillation counting. Plasma was obtained by centrifuging mouse blood at 1,500 r.p.m. in a bench top Eppendorf microcentrifuge and collecting the supernatant. Plasma $(100 \mu \mathrm{l})$ was added to $2 \mathrm{ml}$ of scintillation fluid and ${ }^{3} \mathrm{H}$ levels were determined by scintillation counting Concentration of oligosaccharide in plasma and tissues was derived from the specific activity of the radiolabel (see above).

\section{Extraction and purification of ${ }^{3} \mathbf{H}-12-m e r$ dodecasaccharide 1 from mouse}

kidney. To assess the stability of ${ }^{3} \mathrm{H}$-dodecasaccharide $\mathbf{1}$ in vivo, one animal was dosed with 1 at $20 \mathrm{mg} \mathrm{kg}^{-1}$ for $4 \mathrm{~h}$, and HS was extracted from mouse kidney post mortem using a routine method for HS extraction ${ }^{59}$. The kidneys were dissolved for $16 \mathrm{~h}$ at $60^{\circ} \mathrm{C}$ in $4 \mathrm{M}$ guanidine $\mathrm{HCl} / 8 \mathrm{M}$ urea/1\% Triton in $50 \mathrm{mM}$ Tris, $\mathrm{pH} 8.0$. The extract was diluted 1:100 with water and applied to a $1 \mathrm{ml}$ DEAE-Sephacel (Sigma) ion exchange column pre-equilibrated with PBS. The resin was then washed with $5 \mathrm{ml}$ of $100 \mathrm{mM}$ phosphate buffer with $0.25 \mathrm{M} \mathrm{NaCl}$ to remove hyaluronan and non-GAG material. The oligosaccharide was eluted with $1 \mathrm{M} \mathrm{NaCl}$ in phosphate buffer, concentrated to $1 \mathrm{ml}$ and subjected to size-exclusion HPLC chromatography on a Superdex 75 column in PBS. Fractions $(0.5 \mathrm{ml})$ were collected and counted.

\section{References}

1. Casu, B., Naggi, A. \& Torri, G. Heparin-derived heparan sulfate mimics to modulate heparan sulfate-protein. Matrix Biol. 29, 442-452 (2010).

2. Bishop, J., Schuksz, M. \& Esko, J. D. Heparan sulphate proteoglycans fine-tune mammalian physiology. Nature 446, 1030-1037 (2007).

3. Sasisekharan, R., Shriver, Z., Venkataraman, G. \& Narayanasami, U. Roles of heparan sulphate glycosaminoglycans in cancer. Nat. Rev. Cancer 2, 521-528 (2002). 
4. Hung, K. W. et al. Solution structure of the ligand binding domain of the fibroblast growth factor receptor: role of heparin in the activation of the receptor. Biochemistry 44, 15787-15798 (2005).

5. Olsen, S. K. et al. Insights into the molecular basis for fibroblast growth factor receptor autoinhibition and ligand-binding promiscuity. PNAS 101, 935-941 (2004).

6. Seeberger, P. H. \& Werz, B. Synthesis and medical applications of oligosaccharides. Nature 446, 1046-1051 (2007).

7. Cole, C. \& Jayson, G. C. Oligosaccharides as anti-angiogenic agents. Expert Opin. Biol. Ther. 8, 351-362 (2008).

8. Ikeda, Y. et al. Synthesis and biological activities of a library of glycosaminoglycan mimetic oligosaccharides. Biomaterials 32, 769-776 (2011).

9. Zhao, H. et al. Oligomannurarate sulfate, a novel heparanase inhibitor simultaneously targeting basic fibroblast growth factor, combats tumor angiogenesis and metastasis. Cancer Res. 66, 8779-8787 (2006).

10. Lubineau, A., Lortat, J.-H., Gavard, O., Sarrazin, S. \& Bonnaffé, D. Synthesis of tailor-made glycoconjugate mimetics of heparan sulfate that bind IFN- $\gamma$ in the nanomolar range. Chem. Eur. J. 10, 4265-4282 (2004).

11. Orgueira, H. A. et al. Modular synthesis of heparin oligosaccharides. Chem. Eur. J. 9, 140-169 (2003).

12. de Paz, J. L., Noti, C. \& Seeberger, P. H. Microarrays of synthetic heparin oligosaccharides. J. Am. Chem. Soc. 128, 2766-2767 (2006).

13. de Paz, J. L. et al. The activation of fibroblast growth factors by heparin: synthesis, structure, and biological activity of heparin like oligosaccharides. Chem. Bio. Chem. 2, 673-685 (2001).

14. Hamza, D. et al. First synthesis of heparan sulfate tetrasaccharides containing both $\mathrm{N}$-acetylated and $\mathrm{N}$-unsubstituted glucosamine-search for putative 10E4 epitopes. Chem. Bio. Chem. 7, 1856-1858 (2006).

15. de Paz, J. L., Noti, C., Böhm, F., Werner, S. \& Seeberger, P. H. Potentiation of fibroblast growth factor activity by synthetic heparin oligosaccharide glycodendrimers. Chem. Biol. 14, 879-887 (2007).

16. Tatai, J. \& Fügedi, P. Synthesis of the putative minimal FGF binding motif heparan sulfate trisaccharides by an orthogonal protecting group strategy. Tetrahedron 64, 9865-9873 (2008).

17. Poletti, L. et al. A rational approach to heparin-related fragments; synthesis of differently sulfated tetrasaccharides as potential ligands for fibroblast growth factors. Eur. J. Org. Chem. 14, 2727-2734 (2001).

18. de Paz, J. L., Ojeda, R., Reichardt, N. \& Martín-Lomas, M. Some key experimental features of a modular synthesis of heparin-like oligosaccharides. Eur. J. Org. Chem. 17, 3308-3324 (2003).

19. de Paz, J. L. \& Martín-Lomas, M. Synthesis and biological evaluation of a heparin-like hexasaccharide with the structural motifs for binding to FGF and FGFR. Eur. J. Org. Chem. 1849-1858 (2005).

20. Terenti, O., de Paz, J. L. \& Martín-Lomas, M. Synthesis of heparin-like oligosaccharides on polymer supports. Glycoconj. J. 21, 179-195 (2004).

21. Hung, S.-C. et al. Synthesis of heparin oligosaccharides and their interaction with eosinophil-derived neurotoxin. Org. Biomol. Chem. 10, 760-772 (2012).

22. Lee, J.-C., Lu, X.-A., Kulkarni, S. S., Wen, Y.-S. \& Hung, S.-C. Synthesis of heparin oligosaccharides. J. Am. Chem. Soc. 126, 476-477 (2004).

23. Lu, L.-D. et al. Synthesis of 48 disaccharide building blocks for the assembly of a heparin and heparan sulfate oligosaccharide library. Org. Lett. 8, 5995-5998 (2006).

24. Codée, J. D. C. et al. A modular strategy toward the synthesis of heparin-like oligosaccharides using monomeric building blocks in a sequential glycosylation strategy. J. Am. Chem. Soc. 127, 3767-3773 (2005).

25. Hu, Y.-P. et al. Synthesis of 3-O-sulfonated heparan sulfate octasaccharides that inhibit the herpes simplex virus type 1 host-cell interaction. Nat. Chem. 3, 557-563 (2011).

26. Tiruchinapally, G., Yin, Z., El-Dakdouki, M., Wang, X. \& Huang, X. Divergent heparin oligosaccharide synthesis with preinstalled sulfate esters. Chem. Eur. J. 17, 10106-10112 (2011).

27. Wang, Z. et al. Preactivation-based, one-pot combinatorial synthesis of heparin-like hexasaccharides for the analysis of heparin-protein interactions. Chem. Eur. J. 16, 8365-8375 (2010).

28. Czechura, P. et al. A new linker for solid-phase synthesis of heparan sulfate precursors by sequential assembly of monosaccharide building blocks. Chem. Commun. 47, 2390-2392 (2011).

29. van Boeckel, C. A. A. et al. Synthesis of a pentasaccharide corresponding to the antithrombin III binding fragment of heparin. Carbohydr. Chem. 4, 293-321 (1985).

30. Tabeur, C. et al. Oligosaccharides corresponding to the regular sequence of heparin: chemical synthesis and interaction with FGF-2. Bioorg. Med. Chem. 7, 2003-2012 (1999).

31. Karst, N. A. \& Lindhardt, R. J. Recent chemical and enzymatic approaches to the synthesis of glycosaminoglycan oligosaccharides. Curr. Med. Chem. 10, 1993-2031 (2003).
32. Arndt, S. \& Hsieh-Wilson, L. C. Use of cerny epoxides for the accelerated synthesis of glycosaminoglycans. Org. Lett. 5, 4179-4182 (2003).

33. Yu, H. N., Furukawa, J., Ikeda, T. \& Wong, C.-H. Novel efficient routes to heparin monosaccharides and disaccharides achieved via regio- and stereoselective glycosidation. Org. Lett. 6, 723-726 (2004).

34. Zhou, Y., Lin, F., Chen, J. \& Yu, B. Toward synthesis of the regular sequence of heparin: synthesis of two tetrasaccharide precursors. Carbohydr. Res. 341, 1619-1629 (2006).

35. Arungundram, S. et al. Modular synthesis of heparan sulfate oligosaccharides for structure-activity relationship studies. J. Am. Chem. Soc. 131, 17394-17405 (2009).

36. Xu, Y. et al. Chemoenzymatic synthesis of homogeneous ultralow molecular weight heparins. Science 334, 498-501 (2011).

37. Laremore, T. N., Zhang, F., Dordick, J. S., Liu, J. \& Linhardt, R. J. Recent progress and applications in glycosaminoglycan and heparin research. Curr. Opin. Chem. Biol. 13, 633-640 (2009).

38. Dredge, K. et al. PG545, a dual heparanase and angiogenesis inhibitor, induces potent anti-tumour and anti-metastatic efficacy in preclinical models. Brit. J. Cancer 104, 635-642 (2011).

39. Johnstone, K. D. et al. Synthesis and biological evaluation of polysulfated oligosaccharide glycosides as inhibitors of angiogenesis and tumor growth. J. Med. Chem. 53, 1686-1699 (2010).

40. Zhou, H. et al. M402, a novel heparan sulfate mimetic, targets multiple pathways implicated in tumor progression and metastasis. PLOS ONE 6, e21106 (2011).

41. Ferro, V. et al. Discovery of PG545: a highly potent and simultaneous inhibitor of angiogenesis, tumor growth, and metastasis. J. Med. Chem. 55, 3804-3813 (2012).

42. Wakao, M. et al. Sugar chips immobilized with synthetic sulfated disaccharides of heparin/heparan sulfate partial structure. Bioorg. Med. Chem. Lett. 18, 2499-2504 (2008).

43. Schwörer, R., Zubkova, O. V., Turnbull, J. E. \& Tyler, P. C. Synthesis of a targeted library of heparan sulfate hexa- to dodecasaccharides as inhibitors of $\beta$-secretase: potential therapeutics for Alzheimer's disease. Chem. Eur. J. 19, 6817-6823 (2013).

44. Baleux, F. et al. A synthetic CD4-heparan sulfate glycoconjugate inhibits CCR5 and CXCR4 HIV-1 attachment and entry. Nat. Chem. Biol. 10, 743-748 (2009).

45. Hudak, J. E., Yu, H. H. \& Bertozzi, C. R. Protein glycoengineering enabled by the versatile synthesis of aminooxy glycans and the genetically encoded aldehyde tag. J. Am. Chem. Soc. 133, 161119-16126 (2011).

46. Jayson, G. C. et al. T. Heparan sulfate undergoes specific structural changes during the progression from human colon adenoma to carcinoma in vitro. J. Biol. Chem. 273, 51-57 (1998).

47. Jayson, G. C. et al. Coordinated modulation of the fibroblast growth factor dual receptor mechanism during transformation from human colon adenoma to carcinoma. Int. J. Cancer 82, 298-304 (1999).

48. Whitworth, M. K. et al. Regulation of fibroblast growth factor-2 activity by human ovarian cancer tumor endothelium. Clin. Cancer Res. 11, 4282-4288 (2005).

49. Backen, A. C. et al. Heparan sulphate synthetic and editing enzymes in ovarian cancer. Br. J. Cancer 96, 1544-1548 (2007).

50. Jayson, G. C. \& Gallagher, J. T. Heparin oligosaccharides: inhibitors of the biological activity of bFGF on Caco-2 cells. Br. J. Cancer 75, 9-16 (1997).

51. Hasan, J. et al. Heparin octasaccharides inhibit angiogenesis in vivo. Clin. Cancer. Res. 11, 8172-8179 (2005).

52. Cole, C. L. et al. Synthetic heparan sulfate oligosaccharides inhibit endothelial cell functions essential for angiogenesis. PLoS ONE 5, e11644 (2010).

53. Babu, P. \& Kuberan, B. Fluorescent-tagged heparan sulfate precursor oligosaccharides to probe the enzymatic action of heparitinase I. Anal. Biochem. 396, 124-132 (2010).

54. Xia, B., Feasley, C. L., Sachdev, G. P., Smith, D. F. \& Cummings, R. D. Glycan reductive isotope labeling for quantitative glycomics. Anal. Biochem. 387, 162-170 (2009).

55. Fernandez, C., Hattan, C. M. \& Kerns, R. J. Semi-synthetic heparin derivatives: chemical modifications of heparin beyond chain length, sulfate substitution pattern and N-sulfo/N-acetyl groups. Carbohydr. Res. 341, 1253-1265 (2006).

56. Park, S., Sung, J.-W. \& Shin, I. Fluorescent glycan derivatives: their use for natural glycan microarrays. ACS Chem. Biol. 4, 699-701 (2009).

57. Hansen, S. U. et al. Synthesis and scalable conversion of L-iduronamides to heparin-related di- and tetrasaccharides. J. Org. Chem. 77, 7823-7843 (2012).

58. Hansen, S. U., Miller, G. J., Jayson, G. C. \& Gardiner, J. M. First Gram-scale synthesis of a heparin-related dodecasaccharide. Org. Lett. 15, 88-91 (2013).

59. Lyon, M. \& Gallagher, J. T. Purification and partial characterization of the major cell-associated heparan sulphate proteoglycan of rat liver. Biochem. J. 273, 415-422 (1991). 


\section{Acknowledgements}

We thank the CRUK (C2075/A9106), MRC (G0601746 and G902173) and Holt Foundation for project grant funding; EPSRC for NMR instrumentation (GR/L52246); and we also thank the EPSRC National Mass Spectrometry Service, Swansea, for MS analyses.

\section{Author contributions}

S.U.H. and G.J.M. jointly contributed to the development of iteration and LAT strategies, wrote and finalized manuscript with J.M.G. G.R. conducted the preparation, analysis and purification of tritiated saccharides. C.C. helped in conducting biological experiments. G.C.J. gave overall contribution to project aims. J.M.G. and G.C.J. contributed equally to supervision and planning of this work. E.A., G.R. and G.J. contributed to manuscript biology. J.M.G. supervised synthesis and project planning, and helped in writing and finalizing the manuscript.

\section{Additional Information}

Supplementary Information accompanies this paper at http://www.nature.com/ naturecommunications

Competing financial interests: The authors declare no competing financial interests.

Reprints and permission information is available online at http://npg.nature.com/ reprintsandpermissions/

How to cite this article: Hansen, S. U. et al. Tetrasaccharide iteration synthesis of a heparin-like dodecasaccharide and radiolabelling for in vivo tissue distribution studies. Nat. Commun. 4:2016 doi: 10.1038/ncomms3016 (2013).

(c) $\Theta$ This work is licensed under a Creative Commons Attributioncc. this license, visit http://creativecommons.org/licenses/by-nc-nd/3.0/ 